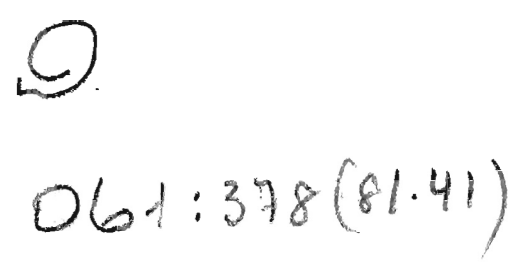

\title{
Sugestões oferecidas pelo prof. Dr. Miguel Reale à reforma do estatuto da Universidade de São Paulo.
}

Senhor Diretor:

Com referência ao anteprojeto do Estatuto da Universidade de São Paulo, sôbre o qual V. Excia. teve a gentileza de pedir meu pronunciamento, vou limitar-me a examinar apenas duas questões, dada a premência de tempo.

1. O assunto que, em primeiro lugar, suscita algumas. observações é o relativo à forma de provimento das cátedras.

Não é de hoje que venho sustentando a necessidade de instaurar-se, definitivamente, no Magistério Superior a formação dos mestres através de um preparo gradativo, marcado pela dedicação e pela experiência em cada ramo do conhecimento.

Para que se estabeleça o regime de carreira no ensino universitário, torna-se necessário superar, de vez, o problema nuclear, que é o de não permitir concurso à cátedra por quem não seja livre docente da disciplina, ou, pelo menos, não apresente, a critério da maioria absoluta da Congregação, trabalho considerado de excepcional valor sôbre matéria da cadeira a preencher *.

Sem se afrontar êsse problema, continuaremos a perseverar em enganos. Ora, nada impede que a lei condicione

*. No Estatuto da Universidade acolheu-se esta sugestão, exigindo-se, porém, a manifestação de dois terços dos membros da Congregação, o que me parece excessivo. 
o acesso às cátedras, subordinando-o à satisfação de um pressuposto, qual seja, o da obtenção do título de livre docente.

2. Alega-se que os cargos são accessíveis a todos os brasileiros, mas não é menos certo que o artigo 184 da Constituição acrescenta esta ressalva fundamental:

"observados os requisitos que a lei estabelecer"

Assim sendo, se a lei de diretrizes e bases é silente sôbre o assunto, inclui-se na competência dos sistemas estaduais do ensino resolver sôbre os pressupostos ou condições de acesso.

O que a Constituição Federal exige é que o provimento das cátedras no ensino superior oficial ou livre se faça sempre mediante concurso de títulos ou provas.

Sôbre êste ponto volverei logo mais, pois julgo necessário fazer-se uma alteração no tocante ao provimento das cátedras", se prevalecer a exigência à qual agora estou me reférindo.

A experiência tem demonstrado que os concursos às cátedras vêm se transformando em oportunidade para a obtenção da livre docência.

Em geral, considera-se mais cômodo obter-se êste título em concurso para a cátedra, por múltiplos motivos, especialmente onde a banca examinadora nas provas para livre docência é composta exclusivamente de professôres da casa.

Infelizmente, professôres estranhos às Faculdades, que integram as mesas de concurso, como que são levados a conferir livre docência, com certa magnanimidade. .

Daí o afluxo de candidatos, sobrecarregando a seleção para a cátedra, ou fazendo passar para um segundo plano o objetivo fundamental que se devia e se deve ter em vista.

Por outro lado, o provimento da cátedra deve obedecer a outros requisitos específicos, notadamente no que se refere ao volume de produção científica, ao significado objetivo das pesquisas realizadas pelo aspirante à mais alta dignidade universitária. 
Isto posto, sugiro que no artigo 87 , onde se diz:

"deverá apresentar diploma de curso universitário, oficial ou reconhecido",

dever-se-ia dizer:

"deverá possuir título de livre docente da disciplina "em concurso, obtido em estabelecimento oficial ou reconhe"cido"

Sugiro, outrossim, que se acrescente o seguinte parágrafo único ao mesmo artigo 87:

"Parágrafo único: - A Congregação, pela maioria ab"soluta dos seus membros, poderá dispensar a exigência de "título de livre docente ao candidato que apresentar traba"lho considerado de excepcional valor sôbre a matéria".

3. Se vier a ser adotada esta minha sugestão, penso que deveria ser suprimida a prova escrita no concurso para cátedra. Aliás, o artigo 90 do anteprojeto só prevê a obrigatoriedade da defesa de tese e da prova didática, deixando a cada estabelecimento a faculdade de incluir, conforme a natureza da matéria, provas escritas e práticas.

Meu pensamento é no sentido de que, nas Faculdades de Direito, pelo menos, assim como naquelas em que prevalece $o$ aspecto teorético, deveria prevalecer a exigência de prova escrita sòmente para o concurso à livre docência. Para o provimento da cátedra a nota tônica deveria ser posta na prova didática e sobretudo na produção científica, no ról dos trabalhos e pesquisas elaborados sôbre a matéria.

Em princípio, não poderia pretender a cátedra o livre docente que tivesse deixado passar anos e anos sem qualquer contribuição à ciência, limitando-se a dar aulas, visto como a pesquisa autônoma é da essência mesma da vida universitária.

4. Merece encômios o dispositivo do anteprojeto que exige fundamentação para a prova de títulos, pois sòmente assim deixará essa nota de ser uma espécie de câmara de compensação, de valor e alcance puramente subjetivo, quando não arbitrário. 
5. Ainda em matéria de concurso penso que se deveria acrescentar ao artigo $92 \mathrm{um}$ outro item, prevendo-se a hipótese, - que em tese não pode ser excluída, - da não indicação de nenhum dos concorrentes para a cátedra.

Não se compreende, em verdade, que um concurso deva ser considerado segundo critérios subjetivos, com o provimento inexorável de um dos aspirantes, ainda quando todos tenham revelado incapacidade para a regência vitalícia da cátedra.

6. A necessidade da prova de livre docência para o concurso à cátedra implicará, como é óbvio, a revisão de vários artigos do anteprojeto, redigindo-se, por exemplo, o parágrafo $2 .^{\circ}$ do artigo 94 da seguinte forma:

"Parágrafo 2." - Ao candidato que alcançar de 3 ou "mais examinadores a média mínima 7, será conferida a "livre docência, se esta houver sido dispensada "ex vi" do "disposto no $\S$ único do artigo 87".

7. Por outro lado, admitida a possibilidade de uma conclusão negativa por parte da banca examinadora, será necessário dar nova redação ao artigo $94, \S 3 .^{\circ}$, artigo 95 e seu $\S$ único, visto como ficará afastada a obrigatoriedade de indicar-se automàticamente para a cátedra o candidato classificado em primeiro lugar.

8. Tenho minhas dúvidas quanto à conveniência de afastar-se completamente a Congregação das provas de concurso, quer para livre docência, quer para a cátedra.

Em verdade, a prevalecer o disposto no artigo 96, a Congregação só terá direito a pronunciar-se em recurso de nulidade contra o resultado apresentado pela Comissão examinadora.

Pràticamente, o que se quer consagrar em lei é, de um lado, o predomínio absoluto da banca examinadora, e, de outro, a abstenção por parte dos professôres, fato êste que, verdade seja dita, vem-se tornando a regra.

Valerá a pena lutar contra a dessídia, ou será melhor convertê-la em lei?! 
Pergunto, outrossim, se uma Congregação deve louvarse exclusivamente no critério da Banca examinadora, só reservando para si o aspecto formal da investidura das cátedras.

Compreendo que em certas Faculdades se torna impossivel a participação da Congregação, pois seria absurdo que um matemático, por exemplo, se pronunciasse vàlidamente sôbre exame de sociologia, filosofia ou literatura grega.

Nas Faculdades de Jurisprudência, onde o conhecimento jurídico é uma estrutura orgânica e solidária, é possível um juízo válido sôbre disciplina que não seja a cultivada diretamente pelo jurista.

Assim sendo, penso que se deveria deixar ao regulamento de cada Faculdade decidir sôbre a forma e a extensão da participação das Congregações nas provas de concurso, mantendo-se os "quorum" de rejeição atuais que já preservam a eminência da Banca examinadora.

9. Parece-me ainda necessário que o Estatuto não se arrede da Constituição federal no que tange à caracterização do professor catedrático.

O Artigo 82 parece-me imperfeito, pois o professor catedrático não é aquêle que ocupa a cátedra em caráter efetivo, mas sim em virtude de concurso de títulos e provas (Constituição federal, artigo 168, n. $^{\circ}$ VI e 187).

A meu ver, o anteprojeto consagra uma distinção entre professor catedrático efetivo e professor catedrático vitalício, sendo a vitaliciedade, nos têrmos do artigo 97, uma decorrência do concurso de títulos e provas...

Ora, essa categorização é inconstitucional: após a Constituição de 1946 só é catedrático, e por conseguinte com vitaliciedade, quem tenha sido aprovado na cátedra graças a concurso de títulos e provas *

* Felizmente, o Estatuto foi explícito na caracterização do que seja "professor catedrático". 
Não ignoro que na Universidade haja "catedráticos" sem concurso de títulos e provas, em virtude das situações configuradas anteriormente à entrada em vigência da Carta Maior de 1946.

Trata-se de regentes de cátedra em caráter efetivo, cujos direitos merecem e devem ser ressalvados, o que é, porém, matéria para disposição de caráter transitório.

Não se compreende, todavia, que daí se parta para se criarem duas espécies de catedráticos, os efetivos (sem concurso) e os vitalícios (com concurso).

10. Uma outra questão que, dada a premência de tempo, me parece merecedora de alguns comentários é a relativa aos auxiliares do ensino.

$\mathrm{Na}$ sistemática do anteprojeto (artigo 110) os auxiliares do ensino compreendem os professôres de disciplina e os assistentes, e como se trata de uma questão de terminologia, nada tenho a dizer quanto ao têrmo "auxiliares de ensino", preferido para designar o gênero, do qual o assistente será uma espécie.

Minha proposta é no sentido de se acrescentar a letra $d$ ao parágrafo $2 .^{\circ}$ do artigo 81 , prevendo-se os "assistentes voluntários".

Assistente voluntário é aquêle que, independentemente de vencimento, salário ou gratificação, é escolhido pelo professor catedrático para dar cooperação à cátedra em trabalhos de seminário e de pesquisa.

Nas Faculdades de turmas numerosas, como é o caso da Faculdade de Direito, sòmente mediante assistentes voluntários será possível realizar, com eficiência, trabalhos de pesquisas em grupos reduzidos de 20 a 25 alunos.

Em outras Faculdades, taiṣ assistentes voluntários são chamados "instrutores" ou "monitores". 
Seria aconselhável que se previsse a possibilidade dessa categoria docente, primeiro degrau na formação da carreira do professor universitário.

São estas, Senhor Diretor, as ponderações que me sugerem o anteprojeto do Estatuto da Universidade. Deixando de examinar outras questões, não desejo deixar de louvar a obra feita em tão breve tempo. 